\title{
Convergent and Nature-Like Technologies as the Basis for Sustainable Development in the 21st Century
}

\author{
Sergey Zhironkin ${ }^{1,2}$, Svetlana Demchenko ${ }^{2}$, Gennady Kayachev ${ }^{2}$, Ekaterina Taran $^{3}$, and \\ Olga Zhironkina ${ }^{4}$ \\ ${ }^{1}$ T.F. Gorbachev Kuzbass State Technical University, 650000 Kemerovo, 28 Vesennya st., \\ Kemerovo, Russia \\ ${ }^{2}$ Siberian Federal University, 660075 Lida Prushinskaya St. 2, Krasnoyarsk, Russia \\ ${ }^{3}$ National Research Tomsk State University, 63405036 Lenin ave., Tomsk, Russia \\ ${ }^{4}$ Plekhanov Russian University of Economics, Kemerovo branch, 650992, pr. Kuznetskiy, 39, \\ Kemerovo, Russia
}

\begin{abstract}
The global challenge of the 21 st century is associated with the need to ensure the sustainable development of modern countries. The basic condition for such development is an adequate amount of energy and resources. This means using not oil and gas only but supplies of drinking water, arable land, forests, and other mineral resources are being rapidly depleted. The industrial civilization, in only 200 years of its existence, has put the world on the threshold of a resource collapse. The reason for the current crisis situation is the antagonism of nature and the technosphere created by man. Technical progress has violated the natural resource turnover - a peculiar metabolism of nature, creating technologies that are hostile to it. These technologies, being torn from the natural context, are in fact bad copies of individual elements of natural processes and are based on a highly specialized model of science and industry-specific technologies. Consequently, the transition to sustainable development requires a radical technological modernization of the economy, in particular, widespread diffusion and inter-sectoral transfer of convergent and nature-like technologies.
\end{abstract}

\section{Introduction}

Modern technologies require a tremendous amount of energy that the existing alternative energy is not capable of working out in principle. Science helps to get out of this technological trap, and already today makes it possible to create fundamentally new technologies for generating and consuming energy on the model of living nature - naturelike technologies. The meaning of creating a nature-like technosphere is to restore the natural, self-consistent resource turnover, disturbed by today's technologies, taken out of their natural context. A tool for creating such a technosphere - convergent nano-, bio-, information, cognitive and socio-humanitarian technologies (NBIC technologies) 
The term nature-like technology has long been familiar to environmentalists and conservationists. However, until recently it was not used at the official level. The main principles of these technologies are:

- use of waste-free recultivating technologies;

- conservation of ecology;

- use of technology in accordance with the laws of nature;

- exclusion from circulation of GMOs and synthesized biologically active components.

The concept of convergent technologies incorporated the merger of nano-, bio- and information technologies. As well as the inclusion of cognitive and social science, which creates equipment, methods, tools and business models that improve economic performance, but at the same time, do not have a negative impact on the environment. In particular, the convergence is based on the reduction of environmental pollution, increasing human productivity and restoring balance in natural processes and cycles.

\section{Materials and Methods}

Today, most of the world's research comes from living objects. Nanobiotechnology, in fact, has already become a new technological culture, where at the atomic level, the lines between the animate and inanimate, between the natural organic world and inorganic, are blurred [1]. Created on the basis of these technologies, new materials and systems are already used in medicine, energy, ecology, transport, etc. The next stage is the reproduction of living systems and processes in the form of a synthetic cell, the mass creation of artificial tissues and organs. Additive technologies now allow creating bioorganic objects using the natural principle of formation, growing them for the market. Along with additive technologies, bioenergy is actively developing, in particular, bioenergy devices are being developed that generate and consume energy using natural metabolic processes in living systems [2].

The next step may be the creation of artificial intelligence for biosimilar and synthetic biological objects based on the achievements of cognitive and information technologies. All of this will gradually form the basis for the nature-like technosphere, which will become an organic part of nature, included in its natural resource and resource management. It can not only preserve civilization, but also give impetus to its development at a fundamentally different level. However, there is a fundamental condition: without a change in our consciousness, attitude to civilization, nature, and to ourselves, these prospects may remain nothing. This emphasizes the socio-humanitarian dimension of the convergence of science and technology. Research and development on the creation of nature-like technologies are actively conducted in a number of foreign countries. In particular, in the USA, in the countries of the European Union, in Japan and in others, hundreds of projects are being implemented in this area [3-5].

Initially, technological convergence became the object of engineering research in the 1990s (M. Castells). Later, M. Roco and W. Bainbridge identified convergent technologies as a synergistic result of interaction between representatives of four spheres of industry science: nano- and computing technologies, genetic engineering, neuroscience [6]. Since 2001, under the auspices of the National Science Foundation of the USA, the so-called NBIC (NBIC) initiative (nanotechnology-biotechnology-IT-cognitive science), which denotes some convergent whole, has been put forward. The connection of technological convergence with the development of the national innovation system was considered by some authors as a combination of isolated trajectories of sectoral innovation development [7-9], and by another-as the integration of innovative processes in the basic and high-tech industries based on digitalization (structural and technological convergence) [10-12].

The first one is already being implemented in the technologies of so-called synthetic biology, which allow producing artificial living systems with desired properties, including 
those that do not exist in nature. The basic element of such systems is an artificial cell with a minimally necessary set of genes, sufficient for life and reproduction. Based on such a cell, both ultra-efficient drugs and means of life prolonging can be created. A good example of new threats associated with the creation of artificial living systems is the possibility of the emergence of new types of drugs. The second type of intervention is associated with the impact on the psycho-physiological sphere of a person in order to control his mind and body. Fundamentally new brain-machine and brain interfaces are being actively developed that allow a person to form a given idea of reality.

Now the creation of integrated man-and-machine systems, controlled from the outside, is on the agenda. The existing network technology base (Internet) allows effectively managing both individual and mass consciousness, using integrated technologies of info-cognitive and socio-humanitarian sciences.

The risks accompanying the creation and development of nature-like technologies increase many times due to a number of specific features inherent in the latter. The most important of them are:

- the dual nature of technology, the blurred boundaries between civilian and military applications and, as a result, the inefficiency of existing means and control technologies; - availability and relative cheapness of technology, the ability to create weapons of destruction even in artisanal conditions, no need for the most complex and extremely expensive delivery systems;

- impossibility to predict all the consequences of the release of artificial living systems into the environment.

\section{Results and Discussion}

A vivid example of the unpredictability of the consequences of the release of artificial living systems into the environment is the crowding out of their natural counterparts, which threatens natural biodiversity. In particular, in India, in the USA and in Canada, there have been cases of transmission from genetically modified plants to wild-growing types of herbicide resistance, which turned them into superweeds [13]. Traditionally, humanity followed the model of controlling the result of technological activity - it suffices to recall the regimes of non-proliferation of nuclear, chemical, and bacteriological weapons. In the case of convergent, nature-like technologies, control is needed already at the stage of development of this new technological structure, since control of the result may be untimely and belated.

Successfully performed convergence will help to restore in the new quality the ideas about the integrity of man and the biosphere, and the Earth itself. In its turn, this will help to advance the human priorities of common sense over the narrow departmental interests of divided benefits. In this approach, convergence is similar to the element of constructive globalization, although even the priority interests of solving global environmental problems will have their opponents.

The objective prerequisite for convergence in our time is the search for a scientific solution to the global problems of the Earth's biosphere and civilization, which we propose to recognize as the global core of the convergence of sciences. As the axes of convergence, we propose to consider the complex problems of the most critical areas of the Earth's biosphere, the solution of which requires combining efforts and sharing the achievements of a number of sciences and areas: the Arctic, oceans, desertification, tropical forests, etc.

From the point of view of productive forces development, technological convergence means a new relocation of industries, both within production chains (including exterritorialy, in network form). As a result of such a relocation, clusters of a new type are formed in which producers of benefits characteristic of the modern round of scientific and technological progress (such as the newest drugs, means of global information access, ecologically clean 
energy sources, etc.) create a "centerless" network form of resources, information and knowhow, labor circulation, and coordinate all the activities on the basis of general economic incentives. Such relocation takes place in the form of global network clusters of convergent technologies that use virtually unlimited sources of investment in the global capital market and a digitalized market of high-intelligence work, creating products that exist mostly in nonmaterial form, extraterritorially created and consumed.

In turn, the convergent technological relocation of the productive forces is integral to the modification of economic relations in the reproduction system. There are the new forms of raising capital (IPO of high-tech companies, crowdfunding, public-and-private high-tech partnerships) and investment of innovations (innovative intrapreneurship, co-investing of developers and consumers). New interconnections of business structures are being formed joining investors, technology developers, owners of resources and the finished product (blockchain, "smart contract"). As a result, labor and capital become so mobile that the depreciation of the means of production tends to zero, and workers constantly increase their competences in the process of combining technologies. In such a system, the relocation of the productive forces and the modification of economic relations, and a whole new industries are created congruently with the interweaving of technologies.

The development of technological convergence modifies structural shifts, expanding the boundaries of industry, changing the market conditions for the future relocation of investment flows, industry, territorial distribution of productive forces as the factors of structural change. At the same time, self-induction of convergent technologies, their ability to quickly capitalize and expand their share in the structure of the economy is due to the interpenetration and recombination of technological innovations developed in different technological platforms, but they are able to provide a common product. Therefore, the structural shifts induced by technological convergence are accompanied by the development of economic relations, the regulation of which by the state with the old instruments (public investment, innovative tax breaks, subsidies) will not lead to the desired effect, but may cause the opposite result.

The relocation and modification role of convergent technologies is explained by their innovative diffuse essence, which makes it impossible to create a single center. On the contrary, their clusters form a polycentric network, in which there is a constant exchange of know-how and joint patenting of breakthrough innovations, the introduction of which is gradually becoming widespread. Accordingly, a convergent structural shift becomes possible only with the participation of the economy in global clusters of convergent technologies: 1. The global cluster of nanotechnologies (production of super-micro-objects of several nanometers $\left(10^{-9} \mathrm{~m}\right)$ in size from individual molecules, the number of which can reach tens of thousands), in which such benefits as materials with new properties, "full health" medicines are created, full cycle reagents for processing raw materials and reducing energy consumption, etc. Italian Veneto Nahotech and French Minalogic employed in nanofabrication electronically are examples of European network "nodes" of a global nanotechnology cluster [14].

2. The cluster of biotechnologies carries out diffusion of innovations connected with the solution of new technological problems in the branches of public health, small energy, food production, computer science, with the help of their living organisms and products of their vital activity. The relocation of the productive forces ensures the development of biotechnologies and their industrial application, and is associated with such closely interacting clusters as Swedish-and-Danish Medicon Valley, the Swiss BioValley, the French Paris BioClast, and the Spanish Catalonia BioRegion [15]. The role of the state as a partner of non-profit organizations and private business is to provide tax incentives for combining funding for the most breakthrough and promising developments.

The relocation of productive forces in clusters of ultramodern nano- and biotechnologies, as well as interconnections between their subjects, takes the form of nano-bio convergence, in 
which a market for new goods and services is being formed (biosensors and biodetectors for health care and medicine, self-generating artificial complexes, microprocessors with biomolecules and proteins for information technology). The global result of the development of interactions between clusters of convergent nano- and biotechnologies for 2014 was the production of innovative goods by more than 1 trillion. dollars and the creation of about 300 thousand jobs in more than 30 countries [16].

3 . The global network cluster of convergent information technologies develops the process of digitization of traditional sectors of the economy (basic and manufacturing industries, education and health, transport and communications, education and medicine). The relocation of the productive forces of such a global cluster goes almost everywhere in technologically developed countries (IT clusters Bangalore in India and Dalyan in China, Silicon Valley in the USA, Russian Skolkovo, etc.).

\section{Conclusions}

Thus, the impact of convergent and nature-like technologies on sustainable development reflects such imperatives of greening industrial production as the adaptation of enterprises to accelerating scientific and technological progress, to greening innovations, to change the role of the state in terms of accelerating reproduction processes. The driving forces of technological convergence include the modification of investment and the changing nature of labor in the process of developing basic research in the areas of NBIC, connection of the market for modern means of production and intellectual capital, transformation of property relations in collective investments, introduction of environmental protection systems based on public-private partnership in innovation sphere.

\section{References}

1. S.A. Zhironkin, K.A. Kolotov, A.E. Genin, F.V. Agafonov, S.A. Kovalevsky, IOP Conf. Ser.: Earth Environ. Sci., 50:1, 012011 (2017)

2. M.A. Gasanov, K.A. Kolotov, K.A. Demidenko, E.A. Podgornaya, O.V. Kadnikova, IOP Conf. Ser.: Earth Environ. Sci., 50:1, 012025 (2017)

3. O. Kalenov, S. Kukushkin, E3S Web of Conf., 41, 04025 (2018)

4. I. Kudryashova, E. Kharlampenkov, N. Zakharova, A. Kolevatova, E3S Web Conf., 41, 02025 (2018)

5. E.A. Gasanov, T.S. Boyko, N.S. Frolova, Economics and Innovation Management, 3, 4-8 (2018) DOI: 10.26730/2587-5574-2018-3-4-8

6. M.C. Roco, W.S. Bainbridge, Converging technologies for improving human performance: nanotechnology, biotechnology, information technology and cognitive science (Kluwer Academic Publishers, New York, 2003)

7. R. Rybár, M. Beer, M. Cehlár, Measurement, 88, 153-164 (2016)

8. E. Rogers, Diffusion of Innovations (Simon and Schuster, London, 2010)

9. A. Andersson, D. Batten, Transportation, 14, 281-293 (2002)

10. R.R. Nelson, National Innovation Systems: A Comparative Analysis (Columbian University Pub., New York, 1993).

11. T. Nickols, W.J. Abernathy, The Origins of High-Tech Venture Investing in America (Harvard Business School Press, Boston, 2018)

12. Ch.I. Johns, Am. Econ. J., 3, 1-28 (2011) 
13. A.G. Koryakov, M.V. Kulikov, Economics and Innovation Management, 4, 16-26 (2018) DOI: $10.26730 / 2587-5574-2018-4-16-26$

14. G. Ruffato, F. Romanato, Int. J. Comp. Math. El., 32:6, 1779-1792 (2013)

15. A. Soler, Bioiberica, 24, 1-3 (2016)

16. S. Moffat, MOJ Proteomics \& Bioinformatics, 2:6, 00068 (2015) 